\title{
ESTUDO SOBRE O AVANÇO TECNOLÓGICO NO COMERCIO ATUAL E SURGIMENTO DE NOVOS MERCADOS DE TRABALHO
}

Luís Fernando Alves da Silva Pedro Ramires da Silva Amalfi Costa

Reginaldo Donizeti Cândido

Mogi Guaçu SP

\begin{abstract}
RESUMO
Este artigo científico tem como objetivo explanar a evolução do mercado, desde sua criação, até os avanços e modificações recorrentes atualmente no mercado digital, criação de e-commerce, explicação do conceito de cauda longa e mudanças de paradigmas trabalhistas, onde percebe-se que é possível ganhar um salário elevado em plataformas gratuitas de entretenimento (Streamer e YouTuber), a criação do e-sport e como ele mudou o cenário do comercio dos jogos atualmente até na forma de adquirir bolsas estudantis em universidades conceituadas como Harvard, MIT, entre outras.
\end{abstract}

Palavras-chave: E-Commerce; E-Sport; YouTuber; Streamer; Cauda Longa. 


\section{INTRODUÇÃO}

A humanidade cresceu muito seu número em um curto espaço de tempo, há 2.000 anos, a população mundial era de 300 milhões de pessoas. Em 1800 alcançou um bilhão. A marca de dois bilhões foi atingida em 1927. Os três bilhões em 1959 e quatro bilhões em 1974. A população do planeta chegou a cinco bilhões em 1987, seis bilhões em 1999 e sete bilhões em 2011. (TERRA, 2011)

O número ideal seria entre 1,5 a 3 bilhões de pessoas.
Atualmente, porém, a população é de 7 bilhões. Ou seja, já
somos mais do que o dobro do que a Terra conseguiria abrigar
de forma sustentável. De acordo com o Fundo de População das
Nações Unidas (UNFPA), três fatores devem ser considerados
para o cálculo: disponibilidade de comida, água e terra; padrão
de consumo e capacidade do planeta de absorver a poluição; e
número de pessoas. Para o pesquisador Alan Weisman, autor de
Contagem Regressiva - A Nossa Última e Melhor Esperança
para um Futuro na Terra, há um paradoxo. Não adianta aumentar
a nossa capacidade de alimentar e manter bilhões de pessoas
vivas se cada vez mais pessoas continuarem nascendo.
(SUPERINTERESSANTE, 2015)

Esses dados, mostram como a tecnologia modificou o cotidiano de toda a humanidade, cada ferramenta desenvolvida, desde uma pedra pontuda até um computador, é responsável por acelerar os meios de produção como plantio, fabricação, consumo e prolongando a vida média proporcionando pessoas que vivem mais a cada geração.

Outra principal causa desse avanço frenético vem do fato da informação não estar restrita (normalmente) em uma sala fechada ou um livro esquecido, mas sim disseminada em diversas plataformas do conhecimento. Hoje é muito mais fácil obter uma informação (ou o mínimo que seja dela) do que a algumas décadas atrás. Pessoas com mais de 30 anos, realizavam seus trabalhos escolares, normalmente, com enciclopédias físicas ou bibliotecas municipais, hoje em dia, para um aluno realizar uma pesquisa, basta retirar do bolso 0 celular, consultar sites de busca como GOOGLE e em menos de 5 minutos não é mais um leigo completo sobre $o$ assunto.

Reparem que os avanços tecnológicos vieram para mudar todo um cenário, antes consolidado, nesse ritmo, é correto afirmar que, o modo de vida atual, não será o mesmo depois de alguns anos. 


\section{EVOLUÇÃO NO E-COMMERCE}

Neste capitulo será abordado de forma resumida o surgimento do comercio até a criação do e-commerce (electronic commerce - comercio eletrônico)

\subsection{PRINCIPIO DO COMERCIO}

Segundo NOGUEIRA (2015): "historicamente, fala-se que o comércio surgiu a partir dos processos de trocas na antiguidade, quando determinados grupos trocavam suas produções por outras".

A princípio, cada família produzia tudo para consumo próprio então todos caçavam, produziam, criavam itens para o cotidiano, algumas vezes, acabavam produzindo mais do que consumiam gerando, assim, um excesso daquele produto que nem sempre poderia ser armazenado e estocado já que poderia estar estragado antes do consumo. Com isso, as famílias ofertavam entre seus conhecidos os produtos estocados em excesso por outros que por algum problema não conseguiram produzir para si.

Ao passar do tempo, as famílias se especializavam na confecção de apenas alguns produtos, produzindo-os com maior quantidade e qualidade do que se tentassem abranger todos. Criando assim os profissionais $\mathrm{e}$ consequentemente as profissões. Não era comum, nessa época, a troca de conhecimento entre profissionais da mesma área, assim o conhecimento era passado apenas entre os próprios familiares.

Outra questão a ser observada é que com a criação desse sistema de profissões, foi necessário o uso mais frequente das trocas de mercadoria para que uma família conseguisse adquirir tudo de que precisava assim, um produtor de calçados poderia adquirir vestimentas ou alimentos através da troca de suas mercadorias produzidas.

Esse sistema permitia que as pessoas não sofressem com o desperdício das suas mercadorias e ainda obtivessem outras, 
cultivadas ou criadas por famílias diferentes. Assim, um produtor de trigo, trocava o expediente de seu trabalho por feijão, arroz, peixes e carnes. Não existia uma quantidade prédeterminada, e a barganha era essencial. Como as trocas eram diretas e sem preços específicos, barganhar era a forma de se conseguir um bom negócio. NOGUEIRA (2015)

Não demorou muito para que começassem brigas entre as trocas, os produtores começavam a sentir falta em uma forma de avaliar o real valor de sua mercadoria, obrigando a criação do sistema de moeda.

\subsection{MOEDAS}

A moeda era usada como pagamento por algum produto. Era feita de forma que pudesse ser facilmente transportada, dividida e que durasse bastante tempo. A primeira utilizada foi o sal, e daí, veio a expressão que usamos até hoje: salário. Depois, vieram outros produtos como as conchas, até surgir o ouro e o dinheiro. NOGUEIRA (2015)

Com a criação das moedas, cada produto valia uma determinada quantidade, gerando assim uma organização do comercio, principalmente nas trocas. Esse sistema é altamente gerenciável e sofre variações diárias, produzindo um ecossistema vivo e independente. Assim se dois profissionais criam um mesmo produto, não necessariamente possuem o mesmo valor. Sendo que um pode ser produzido com produtos de melhor qualidade e melhor acabamento, logo, possuirá um valor superior aos demais produtos concorrentes.

Com o tempo foram surgindo as moedas: ouro, prata, bronze. As coisas foram sendo assimiladas a valor e tinha de haver uma forma de haver essa troca de valor por produto. Dessa forma, surgiram os burgos: local específico onde havia o comércio. Com o surgimento dos burgos surgiram os burgueses, comerciários daquela época. A partir de então a forma de uma coisa ser comprada, vendida ou trocada foi apenas sendo aperfeiçoada. Depois de tanta evolução humana, houveram evoluções na forma de produção e na forma de venda. A revolução industrial veio com o intuito de melhorar e facilitar a produção. A implantação de produtos eletrônicos veio para dar um lazer mais seguro ao cidadão, além de facilitar a comunicação e estreitar os relacionamentos. (CULTURAMIX, 2013)

Outra regra mercadológica é a lei da oferta e da procura, onde quando muitos profissionais produzem o mesmo item porem a procura pelo mesmo não é grande, faz com que aquele produto diminua seu valor, enquanto que se existir 
poucos profissionais produzindo um determinado item e a procura por ele é elevada, permite ao profissional elevar seu valor de mercado.

\subsection{COMECIO ELETRÔNICO}

Segundo CULTURAMIX (2013): "O comércio eletrônico surgiu nos anos 70 , com a finalidade de envio de documentação como ordem de serviço ou contas eletrônicas. A comercialização online começou com a venda de produtos como CDs, livros e produtos palpáveis e tangíveis".

Se considerar uma loja de camisetas localizada fisicamente em uma pequena cidade, pode-se considerar que seu poder de venda é limitado aos moradores próximos ao seu estabelecimento. Porém, quando se utiliza o comercio eletrônico ou e-commerce, seu poder de venda é elevado várias vezes, uma vez que, qualquer pessoa do mundo, com acesso a internet, poderia realizar uma compra em seu estabelecimento.

Um exemplo disso é a Amazon.com, que vendeu milhões de livros Harry Potter, mas a metade do seu faturamento veio de livros com menos de dez unidades vendidas. (BSELLER, 2019).

Quando se pensa no exemplo da Amazon, percebe-se a importância e o poder que um e-commerce exerce atualmente, proporcionando aos lojistas 0 poder de aumentar a gama de seus produtos independente do espaço físico de seus estabelecimentos. Quanto maior a diversidade, maior a probabilidade de possuir ao menos um produto de interesse de seus clientes. Tal prática é conhecido como Cauda Longa.

\subsection{CAUDA LONGA}

O termo Cauda Longa, foi criado pelo escritor Chris Anderson, onde ele afirma que a economia mundial está sofrendo alterações, como pode ser visto na imagem 01 abaixo, existem dois tipos de mercados (mercado de massa e de 
nicho), até um tempo atrás os estabelecimentos físicos apenas investiam em adquirir produtos para venda, quando os mesmo eram de gosto popular, poucos produtos vendiam muito, porém, com o surgimento do Comercio Eletrônico, onde as lojas não eram mais limitadas a estruturas físicas e que, poderiam atender a demanda não só regional, mas um senário mundial, percebeu que se somasse todos os itens com pouca saída (produtos de nicho) eles ultrapassariam, e muito, a venda dos produtos com maior saída (produtos de massa) tornando, assim, interessante, comercialmente falando, a venda de produtos de nicho uma vez que tais itens possuem um poder de crescimento muito elevado (somados todos) do que apenas os itens de massa. (INTERNETINNOVATION, 2019)

Segundo SAGEONE (2019) "Essa teoria demonstra, em linhas gerais, como é possível discriminar os setores de menor popularidade no comércio ou na prestação de serviços".

Um exemplo disso são as livrarias físicas contra as livrarias digitais ou as locadoras de filmes contra os serviços de streaming de vídeo (por exemplo Netflix), entre várias outras como Spotify, Youtube ou lojas digitais. Em cada um desses exemplos o que faz a empresa se destacar é que ela não aposta apenas nos produtos de massa, mas disponibiliza aos seus clientes uma gama de produtos de nicho que agrada a todos.

Figura 1 - Cauda Longa

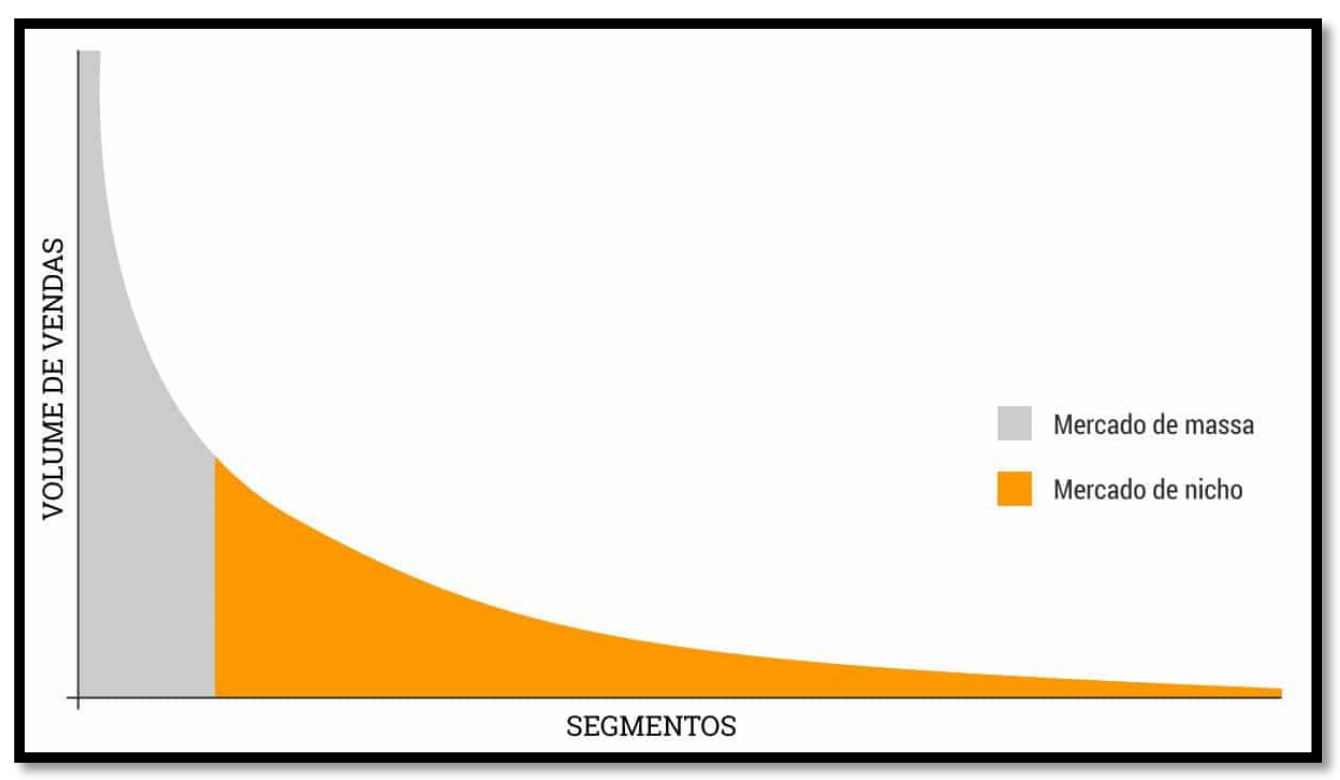

Fonte: RESUMOCAST (2018) 


\section{EVOLUÇÃO NO CENÁRIO DE MERCADO DE JOGOS}

Este capítulo abordará como um dos muitos cenários comerciais foi modificado com o avanço tecnológico, não só se tratando de qualidade visual dos jogos e suas funcionalidades, mas sim sobre um todo, seu comercio, seu público, principalmente após o paradigma da Cauda Longa (já explicado anteriormente no capítulo 2.4).

\subsection{HISTÓRIA DO MERCADO DE JOGOS ATÉ ANOS 2000}

Não há uma exatidão ao se buscar o ponto zero da criação dos jogos digitais porem é possível afirmar que um dos jogos mais antigos que ouviu falar foi o Tennis for Two, desenvolvido pelo físico nuclear norte-americano William Higinbotham nos anos de 1968 que se tratava de um simulador de uma partida de tênis como pode ser visto na imagem 02 abaixo. (JORNADAGEEK, 2018)

Figura 2 - Tennis for Two

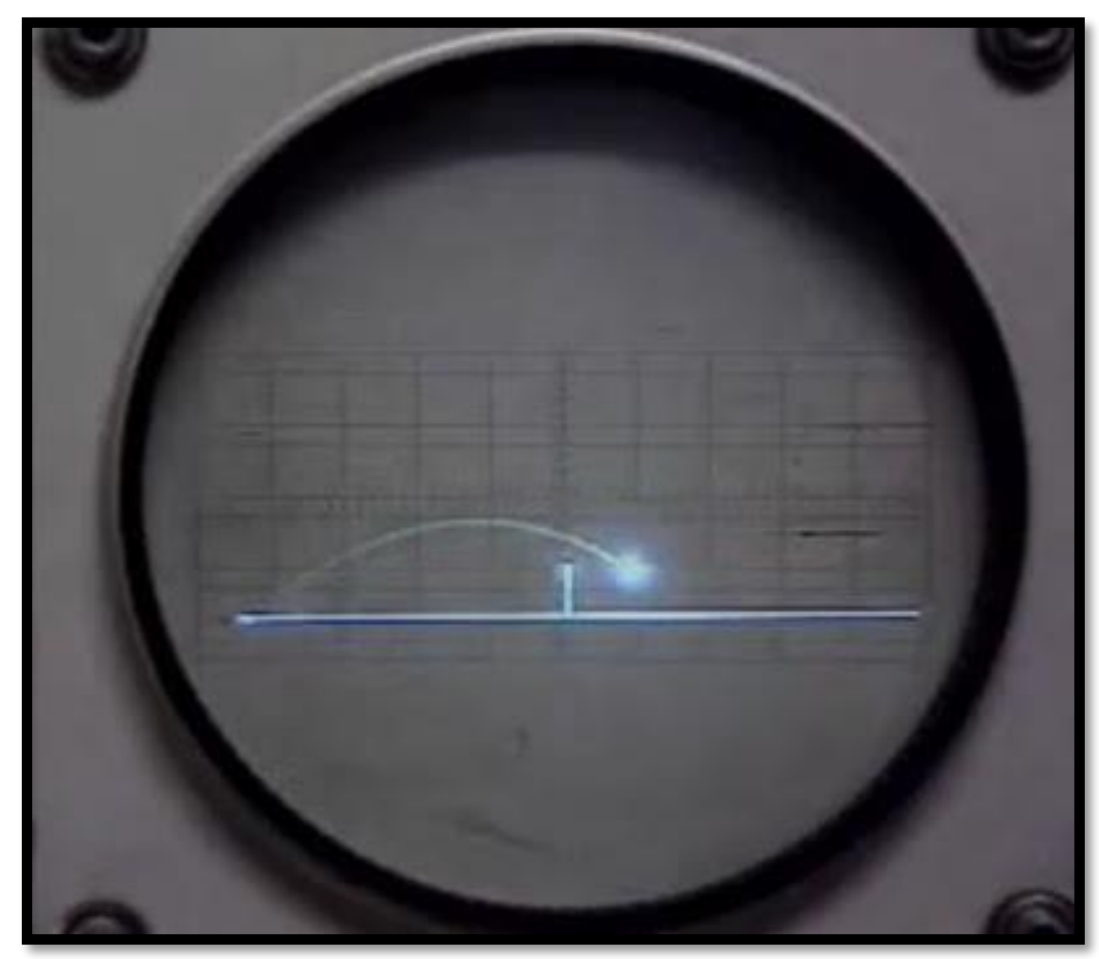

Fonte: ANOSDOURADOS (2012) 
Já o ano de 1961, ficou marcado pelo surgimento do Spacewar!, console desenvolvido pelos estudantes do MIT - Instituto de Tecnologia de Massachusetts, em que dois jogadores controlavam espaçonaves com o objetivo de destruir a do adversário. Apenas ao final da década de 1960 criou-se o primeiro game para TV. Ping-Pong foi a sua invenção de sucesso e um marco na história dos jogos - posteriormente a Atari utilizou-se de uma ideia parecida para introduzir o seu primeiro game no mercado consumidor, o Pong, em 1972, que se tornou um fenômeno. , 2018)

Apesar das diversas invenções até então, a primeira leva de videogames a realmente se tornar popular entre os jovens brasileiros teve início apenas nos anos 80. O console Atari 2600, lançado nos Estados Unidos em 1977, foi o primeiro jogo que virou febre no Brasil, ao chegar ao país em 1983, importado pela marca Polyvox, uma subsidiária da Gradiente, com mais de 500 games disponíveis para esta edição do Atari. Pode -se dizer que a década de 80 marcou história na indústria dos jogos eletrônicos, uma vez que foi neste período que consoles inesquecíveis até os dias de hoje, como Tetris, Super Mario Bros, Ms Pac-Man, entre muitos outros, começaram a surgir e se tornaram clássicos daquela época. 2018)

O grande destaque dos anos 90 vai para o lançamento do Super Nintendo, desenvolvido pela Nintendo para concorrer com o Mega Drive (Genesis, nos EUA). Após anos de sucesso do Super Nintendo, a empresa criou - Nintendo 64, que apesar de possuir certa popularidade, acabou sendo superado em vendas pelo PlayStation, da Sony. 2018)

O novo milênio é marcado pela chegada do PlayStation 2 e da entrada da Microsoft neste segmento com o Xbox, que alcançou rapidamente o segundo lugar do mercado. E daí em diante, os lançamentos continuaram a acontecer: Xbox 360 e Xbox One, Wii e Wii U, PlayStation 3 e 4, e Nintendo Switch, entre outros. 2018)

Repare que nessa época, era comum os jogos virem ao Brasil em sua língua original de produção ou em inglês, sendo poucos títulos traduzidos e até dublados para a língua nacional português do Brasil. Muitos jogadores 
aprenderam a falar, ler e escrever inglês justamente pela ausência de material em português.

\subsection{FUTURO DO MERCADO DE JOGOS}

Segundo estimativas da Newzoo, o mercado mundial de games deve faturar US $\$ 152$ bilhões ainda este ano (2019). A maior fatia desse valor será para os jogos com foco em dispositivos móveis como celulares e tablets que devem gerar um valor aproximado de US $\$ 68,5$ bilhões. A Newzoo também afirma que o mercado de jogos para PCs, até então principal geradora de receitas neste cenário, perderá a coroa e reduzirá a fatia de participação neste mercado até 2022, estima-se perda gradativa anual de $15 \%$. O mercado de games para console permanecerá o mesmo. (EPOCANEGOCIOS, 2019)

A consultoria vê um novo formato de receita crescendo: os "games como serviço", como programas que cobram assinaturas para acesso a jogos ou funcionalidades em jogos. Com esse crescimento, jogos em console devem gerar receitas de US $\$ 47,9$ bilhões, um crescimento de $13 \%$ em relação ao ano anterior. Esse fator deve segurar as receitas em um momento em que a geração atual de consoles está para ser substituída por uma nova. ,2019)

No quesito geográfico, os Estados Unidos devem voltar a ser o maior mercado de videogames do mundo - um posto que havia perdido em 2015 para a China, que agora vê problemas relacionados a liberação de licenças de novos títulos. Os EUA devem alcançar receita de US\$ 36,9 bilhões ao longo de 2019. ,2019)

Mesmo assim, a Ásia seguirá na liderança do mercado de games, gerando receitas estimadas em US\$72,2 bilhões em 2019, o que representa $47 \%$ do valor arrecadada globalmente, segundo o estudo. ,2019)

Na sequência, estão os mercados da América do Norte (US\$ 39,6 bilhões); Europa, Oriente Médio e África (US $\$ 34,7$ bilhões); e América Latina (US $\$ 5,6$ bilhões). ,2019) 
O mercado de games no Brasil deve crescer em torno de 5,3\% até 2022, conforme resultado apresentado pela 19 ${ }^{\text {a }}$ Pesquisa Global de Entretenimento e Mídia, da PwC. No ano passado, o faturamento do setor no país atingiu 1,5 bilhão de dólares, mantendo a posição de líder latino-americano e 13ํㅡ na classificação global. (EXAMEABRIL, 2019)

Com o crescimento do cenário nacional na compra de jogos, as empresas começaram a dar um valor maior ao lançar jogos no Brasil, antes percebia-se um pequeno número de títulos na língua brasileira, atualmente, houve uma inversão de valores, onde são raras as vezes que um jogo não é lançado com a língua brasileira como opção (pelo menos de legenda). É uma postura mundial, não só pela língua brasileira, mas os principais jogos, quando lançados, tomam um cuidado maior para atender todos neste mercado tentando incluir uma grande quantidade de línguas.

\subsection{CAMPEONATOS DE JOGOS DIGITAIS (E-SPORT)}

As origens do esporte eletrônico (e-sports) estão, possivelmente, na Coreia do Sul e em alguns pontos da Ásia e Europa. Os jogos do gênero de estratégia em tempo real cresceram nesses locais, além de levarem ainda popularidade aos jogadores profissionais que surgiram na onda. Na Coreia do Sul, por exemplo, o e-sport é uma modalidade competitiva reconhecida oficialmente desde o ano 2000. (VINHA,2019)

Com o crescimento de diversos jogadores em um mesmo título de jogo, foram criados torneios (normalmente patrocinados pela empresa desenvolvedora do jogo) que investem muito não só para fomentar a quantidade de jogadores, mas também como forma de agradar (gerando mais conteúdo e competição) e fidelizar seus jogadores. Em um cenário tão competitivo, os ganhadores de grandes torneios tornam-se celebridades da noite para o dia, além de gerar valores substanciais de prémios.

Atualmente, o gênero mais popular usado nos e-sports é o Moba, graças ao sucesso de jogos como League of Legends e Dota 2. Com premiações 
gigantescas, os torneios mundiais desses games deram exemplo a outros que tentam seguir, como Heroes of the Storm, Heroes of Newerth e Smite. Dota 2, por exemplo, pagou mais de US\$18 milhões no total em premiação do seu torneio mundial de 2015 - o chamado The International 5. , 2019)

O EVO, ou Evolution Championship Series, é um campeonato internacional de jogos de luta, que ocorre anualmente em Las Vegas. Ao contrário dos outros e-sports, nesse torneio há diversos games, com tabelas e campeonatos separados. Mortal Kombat X, Ultra Street Fighter 4, Super Smash Bros. Melee, Killer Instinct e Tekken 7 foram alguns dos jogos participantes na edição de 2015. Assim como nos outros e-sports, também há os grandes astros, como Daigo Umehara, que é até mesmo patrocinado por uma marca relacionada com o gênero, a fabricante de controles de jogos de luta Madcatz.

Com o crescimento dos jogos de cartas virtuais, segmentos de e-sports têm crescido neste sentido. O líder, claro, é Hearthstone: Heroes of Warcraft, da Blizzard. Ao longo do ano jogadores disputam vagas em eliminatórias, que dão o direito de competir no torneio Mundial, que geralmente ocorre dentro da BlizzCon, o evento oficial para fãs da Blizzard, nos Estados Unidos. Em 2014 a premiação para o primeiro lugar foi de US\$100 mil. , 2019)

No Brasil, o e-sport ainda está crescendo, apesar de ser um gênero de competição já bem popular. O game mais famoso neste sentido por aqui é o League of Legends, graças ao suporte dado pela produtora Riot Games em torneios oficiais, como o Campeonato Brasileiro, ou CBLoL, como também é chamado. Jogos como Counter-Strike, Street Fighter e Fifa também possuem torneios locais, porém menores. Além disso, eventos como Brasil Mega Arena e Brasil Game Show promovem seus próprios torneios de e-sports, contemplando diferentes jogos e com premiações variadas. ,2019)

Bolsas de estudo para atletas são normais no Estados Unidos. Futebol americano, basquete, beisebol... E agora também esportes eletrônicos. Protagonistas de um mercado com cifras impressionantes, as modalidades virtuais ganham cada vez mais espaço nas universidades americanas. Prova disso é o brasileiro Giordano Pereira, de 20 anos - estudante e jogador de League of Legends pela Missouri Valley College. (SPORTV, 2018) 
Ele chegou a ganhar um campeonato em Curitiba, em 2017, mas não a ponto de se tornar famoso no cenário nacional. A ideia de estudar nos Estados Unidos com uma bolsa de estudos para atletas surgiu em um grupo no Facebook. Porém, a vaga na universidade dependia de um processo seletivo, que foi intermediado pela MVP Exchange, uma agência especializada em intercâmbio esportivo. Após entrevista com o técnico do time de LoL, Giordano foi aprovado. Partiu para os EUA e entrou de cabeça em uma rotina de determinação. (_,2018)

No Brasil, as Atléticas com espaço dedicado aos eSports têm se espalhado também, ainda que com investimento mais discreto. O TUES (Torneio Universitário de eSports) é o representante do competitivo mais relevante deste contexto. Giordano acredita que o desenvolvimento passa muito por um conceito que deve surgir desde a época do colégio. ,2018)

A intenção do jovem, agora, é inspirar mais promessas do eSport brasileiro a buscarem o sonho de aliar os estudos em uma grande universidade à carreira nos games. Para isso, ele criou um canal no YouTube e passou a mostrar o seu dia a dia fora do país. ,2018)

\subsection{STREAMERS E YOUTUBERS - NOVAS PROFISSÕES}

Com a evolução tecnológica, computadores cada vez mais rápidos e internet rápida e com preços acessíveis, faz com que um dos principais tormentos para quem viveu antes do novo milénio (assistir filmes e vídeos na internet) se torne um dos principais meios de entretenimento atualmente.

Existem atualmente diversos sites que disponibilizam de forma gratuita ou paga vídeos e filmes para seus usuários poderem assistir, pode-se citar sites como YouTube e Netflix.

Outra forma de comum entretenimento, e que a cada ano vem crescendo mais, são as redes sociais, Facebook, Twitter, Instagram, entre outras que permite aos seus usuários compartilhar informação, noticia, receitas, fotos, vídeos, entre outras coisas, de caráter pessoal ou de conhecimento público. As 
redes sociais permitem que pessoas que já fizeram parte de seu convívio se reencontrem (colegas de escola, trabalho, familiares, amigos) como também dá a oportunidade de ver e acompanhar um pouco do dia-a-dia de alguma pessoa famosa (o que antes só era possível através de revistas de fofocas).

As redes sociais abriram a oportunidade para promover uma "cauda longa" de celebridades, uma vez que não é necessário ter feito um filme ou novela, ser um cantor ou atriz já consagrado para possuir diversos seguidores em suas redes sociais e/ou canais do YouTube, basta ser criativo, cativar as pessoas e ser carismático. Todos podem se tornar famosos dentro de um nicho que não é muito explorado pela televisão, mas que pode ser muito explorado online.

As empresas estão deixando de promover propagandas em televisão para investir em campanhas pessoais com esse novo modelo de celebridade, assim eles alcançam diretamente seu público alvo e gastam muito menos, podendo investir em diversas celebridades o valor que gastaria com apenas um comercial (que não tem muita chance de gerar retorno sobre tal investimento). Pensando nesse novo modelo de investimento em marketing, empresas como YouTube, pagam para os seus influenciadores valores substancialmente altos, conforme o maior número das visualizações nos seus canais.

O site Social Blade fez algumas estimativas em 2017 levando em conta diferentes métricas, como número de inscritos e de visualizações de cada canal. Isso possibilita ter uma ideia de quanto é a renda do Youtuber através unicamente da plataforma de vídeos. Lembrando que as webcelebridades também costumam faturar com outras fontes, como merchans, patrocínios e comerciais. (MATILDEFILMES, 2017)

Pode ser visto uma lista de 2017 dos 10 principais canais no YouTube aqui no Brasil:

$10-5$ inco Minutos

Kéfera, ou simplesmente Ké (como seus fãs a chamam), é a dona do 5inco minutos, criado em 2011 e um dos primeiros canais do YouTube a atingir 1 milhão de inscritos no Brasil. 
Número de inscritos: 10,3 milhões

Visualizações no canal desde a criação: 821 milhões

Ganhos anuais: entre $\mathrm{R} \$ 96$ mil e $\mathrm{R} \$ 1,5$ milhões de reais

9 - Manual do Mundo

Em 2008, o casal lberê Thenório e Mariana Fulfaro, criou um website com a intenção de aproximar a ciência dos internautas. Este website gerou 0 canal do YouTube, conhecido como Manual do Mundo, com postagens semanais de experiências pra lá de divertidas!

Número de inscritos: 7,7 milhões

Visualizações no canal desde a criação: 1,3 bilhões

Ganhos anuais: entre $\mathrm{R} \$ 280$ mil e $\mathrm{R} \$ 3,4$ milhões de reais

8 - Eu fico loko

Em 2010, com apenas 15 anos de idade, Christian Figueiredo criou 0 canal Eu fico loko. Ao longo dos anos, assim como outros Youtubers, ele diversificou suas atividades, criou um segundo canal e hoje trabalha também como ator, escritor e apresentador.

Número de inscritos: 8 milhões

Visualizações no canal desde a criação: 584 milhões

Ganhos anuais: entre $\mathrm{R} \$ 250$ mil e $\mathrm{R} \$ 4$ milhões de reais

7 - CanalCanalha

Com a morte de seu cachorro muito querido, Júlio Cocielo criou despretensiosamente, em 2011, o CanalCanalha. Em 2016, o canal se tornou o terceiro maior do YouTube no Brasil! 
Número de inscritos: 12,1 milhões

Visualizações no canal desde a criação: 769 milhões

Ganhos anuais: entre $R \$ 270$ mil e $R \$ 4,3$ milhões de reais

6 - Coisa de Nerd

O canal criado por Leon Martins e Nilce Moretto, em 2010 tem como temática jogos eletrônicos. Coisa de Nerd é um dos poucos canais brasileiros a ultrapassarem a marca de 1 bilhão de visualizações!

Número de inscritos: 6,4 milhões

Visualizações no canal desde a criação: 1,4 bilhões

Ganhos anuais: entre $\mathrm{R} \$ 390$ mil e $\mathrm{R} \$ 6,1$ milhões de reais

5 - Porta dos Fundos

Canal de comédia que dispensa apresentações! Iniciado em março de 2012, manteve-se por 3 anos como o maior canal brasileiro do YouTube, sendo ultrapassado em 2016 por Whindersson Nunes (nosso próximo da lista) e se encontra hoje na segunda colocação.

Número de inscritos: 13 milhões

Visualizações no canal desde a criação: 3 bilhões

Ganhos anuais: entre $\mathrm{R} \$ 450$ mil e $\mathrm{R} \$ 7,1$ milhões de reais

4 - whinderssonnunes

Whindersson Nunes, com apenas 22 anos, é dono do maior canal brasileiro no YouTube. Com vídeos de comédia o Youtuber é considerado o segundo mais influente no mundo ficando atrás apenas do sueco Felix Arvid Ulf Kjellberg. É mole? 
Número de inscritos: 18,3 milhões

Visualizações no canal desde a criação: 1,3 bilhões

Ganhos anuais: entre $\mathrm{R} \$ 797$ mil e $\mathrm{R} \$ 12,6$ milhões de reais

\section{3 - Felipe Neto}

Com o canal Não Faz Sentido, Felipe Neto ficou famoso com vídeos que possuíam forte tom cômico e crítico e acabou sendo o dono do primeiro canal brasileiro a alcançar 1 milhão de inscritos. Em 2014 porém abandonou o projeto e ficou até 2016 sem postar vídeos, quando resolveu criar o canal Felipe Neto, que cresceu rapidamente.

Número de inscritos: 9,6 milhões

Visualizações no canal desde a criação: 920 milhões

Ganhos anuais: entre $\mathrm{R} \$ 891$ mil e $\mathrm{R} \$ 14$ milhões de reais

2 - rezendeevil

No auge de sua juventude, com 20 anos, Pedro Afonso Rezende é o criador do canal rezendeevil, que faz gameplays do jogo Minecraft e vídeos sobre sua rotina. RezendeEvil, como ele próprio é conhecido pelos fãs, é um estouro, ocupando o posto de maior youtuber de games do Brasil!

Número de inscritos: 11 milhões

Visualizações no canal desde a criação: 3,8 bilhões

Ganhos anuais: entre $R \$ 1,4$ e $R \$ 22,2$ milhões de reais

1 - AuthenticGames

Marco Túlio Matos Vieira, também com 20 anos, é dono do canal AuthenticGames, que conta estratégias e dá dicas sobre o jogo Minecraft, 
chegando a publicar 3 vídeos por dia. O youtuber mais bem pago do Brasil não para de crescer!

Número de inscritos: 9 milhões

Visualizações no canal desde a criação: 3,6 bilhões

Ganhos anuais: entre $R \$ 1,4$ e $R \$ 23,2$ milhões de reais

Ao contrário dos Youtubers que são pessoas cujas quais pode falar e fazer o que quiser (mediante leis internas do site YouTube) variando seus canais e assuntos dentro do seu canal, indo de culinária, conhecimento e tecnologia, até falar sobre seu dia-a-dia, desafios e passeios. Os Streamers são pessoas que compartilham seu dia-a-dia em plataformas de jogos, sempre jogando algo independente de qual plataforma seja, pode ser celular, tablet, PC, console, mas sempre jogando, alguns momentos, durante as suas lives, pode ocorrer uma conversa ou assunto diverso e não relacionado a algum jogo, porém o principal foco de todo Steramer é jogar, falar sobre o jogo e conteúdo relacionado a isso.

Para ser um Streamer hoje em dia, existe diversas opções, mas sem dúvida nenhuma, a principal plataforma para os Streamers é a Twitch. Outra diferença entre um Streamer e um YouTuber é que se comparar a quantidade de visualizações no YouTube e na Twitch, um streamer ganha muito menos por visualização do que um youtuber ganharia pelo mesmo valor. Lembrando que isso não impede de ver casos onde os streamers ganham valores absurdos mensalmente como no caso do streamer brasileiro Ninja que confirmou ganhar por mês em torno de US\$500 mil, mas sim que são mais difíceis de ocorrer. (STREAMIE, 2018) 


\section{CONCLUSÃO}

Com o texto, é possível perceber que a forma como o ser humano vive e faz negócios está em constante mudança, algumas profissões deixarão de existir para que outras surjam. A forma como é consumido a mídia, os produtos, o comércio, industrias, sofreram drásticas alterações em um período de poucas décadas.

Em poucos anos foi possível ver uma pessoa que possui uma câmera, acesso à internet e um computador, não necessariamente com um diploma superior, ter a oportunidade de ganhar uma renda salarial mensal superior a uma das profissões mais consagradas de todos os tempos (médicos) que dedicaram pelo menos 10 anos de suas vidas após ensino médio de estudos e especializações para exercer a profissão.

Ver que as empresas estão cada vez mais focadas em conseguir agradar seus clientes não a um gosto geral, mas a gostos de nicho. Hoje, quando vai se comprar um celular, é possível modificar elementos físicos de design que o deixam exclusivo, fazendo com que poucas pessoas no mundo tenham um celular parecido com o do cliente. Não só celulares, mas muitas lojas estão apostando hoje nessa funcionalidade onde quem produz $\mathrm{o}$ acabamento final dos produtos é o próprio usuário e não mais um padrão estipulado por um gosto geral das massas de clientes consumidores.

As profissões que hoje existem, as áreas mercadológicas, os empregos, o cotidiano de cada indivíduo e até os produtos consumidos hoje, podem, em um

período muito curto, deixarem de existir ou serem modificados e adaptados a uma nova realidade. 


\section{REFERÊNCIAS}

ANOSDOURADOS

URL

(http://www.anosdourados.blog.br/2012/06/imagens-velharia-tennis-for-two-

o.html) visto em 10/09/2019 publicado em 15/06/2012.

BSELLER - URL (https://www.bseller.com.br/o-que-e-e-commerce/) visto em 04/09/2019.

CABRAL - URL (https://brasilescola.uol.com.br/economia/lei-da-ofertae-procura.htm) visto em 04/09/2019.

CULTURAMIX - URL (https://tecnologia.culturamix.com/tecnologias/aevolucao-do-comercio-eletronico) Visto em 27/08/2019 publicado em 20/12/2013.

EPOCANEGOCIOS $-$ URL (https://epocanegocios.globo.com/Empresa/noticia/2019/06/mercado-degames-deve-gerar-receita-de-us-152-bilhoes-em-2019.html) visto em 11/09/2019 publicado em 25/06/2019.

EXAMEABRIL - URL (https://exame.abril.com.br/negocios/mercado-degames-no-brasil-deve-crescer-53-ate-2022-diz-estudo/) visto em 11/09/2019 publicado em 03/08/2019.

INTERNETINNOVATION

URL

(https://www.internetinnovation.com.br/blog/entenda-o-que-e-cauda-longa-ecomo-a-segmentacao-do-conteudo-pode-melhorar-seus-resultados/) visto em 10/09/2019.

JORNADAGEEK $-$

URL

(https://www.jornadageek.com.br/colunas/conheca-a-evolucao-dos-jogoseletronicos-no-brasil-e-no-mundo-pagina-7/) visto em 10/09/2019 publicado em 04/04/2018.

MATILDEFILMES - URL (http://www.matildefilmes.com.br/quantoganha-um-youtuber-famoso-veja-os-10-mais-do-brasil/) visto em 11/09/2019 publicado em 27/03/2017. 
NOGUEIRA - URL (https://www.estudopratico.com.br/historia-docomercio/) Visto em 04/09/2019 publicado em 29/07/2015.

RESUMOCAST - URL (https://www.resumocast.com.br/artigo-caudalonga/) visto em 10/09/2019 publicado em 02/05/2018.

SAGEONE - URL (https://br.sageone.com/2015/01/23/entenda-caudalonga-de-uma-vez-por-todas/) visto em 10/09/2019.

SPORTV - URL (https://sportv.globo.com/site/e-sportv/noticia/combolsa-de-estudos-de-esports-nos-eua-brasileiro-quer-inspirar-novaspromessas-no-pais.ghtml) Visto em 11/09/2019 publicado em 24/09/2018.

STREAMIE - URL (https://streamie.com.br/ninja-quanto-ganha-comstreams/) visto em 11/09/2019 publicado em 19/03/2018.

SUPERINTERESSANTE - URL (https://super.abril.com.br/mundoestranho/quantos-seres-humanos-a-terra-seria-capaz-de-suportar/) visto em 21/08/2019 publicado em 30/07/2015.

TERRA - URL (https://www.terra.com.br/noticias/mundo/onu-divulgaprojecao-sobre-populacao-mundial-vejanumeros,ce08df4cd85ea310VgnCLD200000bbcceb0aRCRD.html) visto em 21/08/2019 publicado em 26/10/2011.

VINHA $-$

URL (https://www.techtudo.com.br/noticias/noticia/2015/10/entenda-o-que-e-esporte-saiba-como-ele-virou-uma-febre-mundial.html) acessado em 11/09/2019. 